Pesq. Vet. Bras. 26(1):47-50, jan./mar. 2006

\title{
Teste de ELISA indireto para o diagnóstico sorológico de $^{\text {pitiose }}{ }^{1}$
}

\author{
Janio M. Santurio ${ }^{2 *}$, Alexandre Trindade Leal ${ }^{3}$, Adriana B. Monteiro Leal ${ }^{3}$, Sydney \\ Hartz Alves ${ }^{2}$, Irina Lübeck ${ }^{4}$, Josiane Griebeler ${ }^{4}$ e Marina Venturini Copetti ${ }^{4}$
}

\begin{abstract}
Santurio J.M., Leal A.T., Leal A.B.M., Alves S.H., Lübeck I., Griebeler J. \& Copetti M.V. 2006. [Indirect ELISA for the serodiagnostic of pythiosis.] Teste de ELISA indireto para o diagnóstico sorológico de pitiose. Pesquisa Veterinária Brasileira 26(1):47-50. Departamento de Microbiologia, Universidade Federal de Santa Maria, prédio 20, sala 4139, Lapemi, Santa Maria, RS 97105-900, Brazil.E-mail: santurio@smail.ufsm.br

Pythiosis is a granulomatous disease caused by the oomycete Pythium insidiosum that affects humans and animals, especially horses. Deaths are very often the consequence of incorrect or late diagnosis when animals no longer respond to treatment. This study aimed standardization of the ELISA assay for the serodiagnostic of pythiosis in horses and rabbits, in order to minimize errors and delays in the diagnosis of the disease. Sera of 72 healthy and 44 of by pythiosis affected horses were used for development and evaluation of the test. The ELISA for equine diagnostic showed $97.72 \%$ sensitivity, $90.27 \%$ specificity, $86 \%$ positive predictive value, $98.4 \%$ negative predictive value, and $93.1 \%$ efficiency. The rabbit test was standardized with 48 sera of healthy rabbits and 24 sera of rabbits immunized with $P$. insidiosum antigens. The results were $91.66 \%$ sensitivity, $95.83 \%$ specificity, $91.66 \%$ positive predictive value, $95.83 \%$ negative predictive value, and $94.44 \%$ efficiency. It can be concluded that ELISA is a reliable test for diagnostic and serological monitoring of pythiosis.
\end{abstract}

INDEX TERMS: Pythium insidiosum, pythiosis, ELISA, horses, rabbits.

RESUMO.- A pitiose, doença granulomatosa de eqüinos causada pelo oomiceto Pythium insidiosum, tem como característica a evolução rápida seguida de morte dos animais. Estas mortes muitas vezes são causadas por diagnósticos errôneos ou demorados quando os doentes já não respondem ao tratamento. Este trabalho teve por objetivo a padronização do ensaio imunoenzimático indireto (ELISA) para diagnóstico sorológico de pitiose em eqüinos e coelhos, visando a diminuição de erros e de tempo necessário para o diagnóstico. Para o desenvolvimento e validação do teste foram utilizadas 72 amostras de soro de eqüinos saudáveis e 44 soros de eqüinos com pitiose confirmada. Os resultados da validação do ELISA para eqüinos foram: sensibili-

\footnotetext{
${ }^{1}$ Recebido em 21 de junho de 2005.

Aceito para publicação em 7 de novembro de 2005.

Trabalho realizado com o auxílio financeiro do PRODETAB - EMBRAPA.

${ }^{2}$ Depto Microbiologia, Universidade Federal de Santa Maria, prédio 20, sala 4139, Lapemi, Santa Maria, RS 97105-900. * Autor para correspondência. E-mail: santurio@smail.ufsm.br

${ }^{3}$ Pesquisador do Laboratório de Pesquisas Micológicas (Lapemi), UFSM, RS.

${ }^{4}$ Aluna de graduação do Curso de Medicina Veterinária, UFSM.
}

dade $97,72 \%$, especificidade $90,27 \%$, valor preditivo positivo $86 \%$, valor preditivo negativo $98,4 \%$ e eficiência de $93,1 \%$. Para coelhos, o teste foi padronizado com 48 amostras de soro de animais saudáveis e 24 amostras de coelhos imunizados com antígenos de $P$. insidiosum. Os resultados foram: sensibilidade $91,66 \%$, especificidade $95,83 \%$, valor preditivo positivo $91,66 \%$, valor preditivo negativo 95,83\% e eficiência de $94,44 \%$. Os resultados deste trabalho demonstram que o ensaio imunoenzimático indireto é um método seguro e eficaz para o diagnóstico sorológico da pitiose.

TERMOS DE INDEXAÇÃO: Pythium insidiosum, pitiose, ELISA, eqüinos.

\section{INTRODUÇÃO}

A pitiose é uma doença cutânea, gastrointestinal ou multissistêmica que pode afetar eqüinos, caninos, bovinos, felinos e humanos, ocorrendo em regiões tropicais e subtropicais (Foil 1996, Santurio et al. 1998, Leal et al. 2001b). O agente causador da pitiose, Pythium insidiosum, é um organismo filamentoso encontrado em ambientes aquáticos, especialmente em regiões pantanosas com temperaturas superiores a $25^{\circ} \mathrm{C}$, como no Pantanal mato-grossense (Leal et al. 2001a). P. insidiosum é produtor de 
zoósporos móveis, sendo atualmente classificado no reino Stramenopila, filo Oomycota (Alexopoulos et al. 1996, Vanittanakom et al. 2004). A doença é endêmica em algumas regiões do mundo, como no Pantanal brasileiro. Nos animais, especialmente em eqüinos, a enfermidade caracteriza-se pela formação de granulomas cutâneos e subcutâneos, e no trato gastrointestinal apresenta-se principalmente na espécie canina (Mendoza et al. 2005). Órgãos e tecidos como pulmão, linfonodos e ossos são raramente atingidos (Chaffin et al. 1992, Leal et al. 2001b). Em humanos a enfermidade caracteriza-se pelo desenvolvimento de lesões cutâneas, oftálmicas ou arterites (Imwidthaya 1994). A pitiose causa prejuízos significativos na criação de eqüinos no Brasil, seja pela morte dos animais, pela perda de função ou pelos gastos com tratamentos (Leal et al. 2001a). O tratamento é complicado pelas dificuldades no diagnóstico e pelas características do agente, que não apresenta esteróis de membrana, sendo portanto resistente à maioria das drogas antifúngicas (Foil 1996).

O diagnóstico da pitiose baseia-se nas características clínicas, histopatológicas e isolamento do agente. Entretanto, por esses métodos o diagnóstico precoce é difícil e requer diferenciação de outras lesões granulomatosas e/ou identificação microbiológica do agente, muitas vezes complicada pelas contaminações secundárias (Chaffin et al. 1992, Leal et al. 2001a). Métodos como imunohistoquímica (Brown et al. 1988), imunodifusão (Miller \& Campbell 1982, Kaufman et al. 1990), ensaio imunoenzimático ELISA (Mendoza et al. 1997) e, mais recentemente, os métodos moleculares (Grooters \& Gee 2002, Schurko et al. 2004, Vanittanakom et al. 2004) tem sido empregados no diagnóstico de pitiose. A técnica de ELISA, primeiramente descrita por Mendoza et al. (1997), tem sido empregada como um método seguro e eficaz para o diagnóstico precoce em humanos e animais (Santurio et al. 2001, Vanittanakom et al. 2004).

Este trabalho teve por objetivo descrever o desenvolvimento e a padronização de um ensaio imunoenzimático indireto (ELISA) para a detecção de anticorpos contra Pythium insidiosum no soro de eqüinos e de coelhos.

\section{MATERIAL E MÉTODOS}

Amostras de soro. Foram analisadas 72 amostras de soro de eqüinos sadios, 44 amostras de eqüinos com pitiose clínica, 48 amostras de soro de coelhos sadios e 24 amostras de soro de coelhos imunizados com antígenos de Pythium insidiosum.

Preparação do antígeno. Fragmentos de cultivos de $P$. insidiosum DMVP 118/98 (CBS 101555) foram inoculados em caldo Sabouraud dextrose e incubados a $37^{\circ} \mathrm{C}$ sob agitação de $120 \mathrm{rpm}$ durante 6-7 dias. A cultura, após inativação com timerosal $(0,02 \%)$ foi filtrada. A massa fúngica retida foi pesada e ressuspendida (1 $\mathrm{g}$ massa fúngica/ $5 \mathrm{ml}$ PBS) em tampão fosfato $0,02 \mathrm{M} \mathrm{pH} \mathrm{7,4}$. Essa massa foi sonicada ( 23 watts com pulsos de 30 segundos durante 3 minutos) em banho de gelo. $O$ material resultante da sonicação foi centrifugado a 7.000 rpm durante 15 minutos e o sobrenadante obtido foi coletado como antígeno solúvel. A concentração de proteínas foi determinada pelo método de Lowry modificado, usando albumina bovina como padrão $(1 \mathrm{mg} / \mathrm{ml})$.

Sensibilização das placas e realização do teste. Placas de poliestireno de 96 poços, fundo plano (Corning Costar Corporation,
Cambridge, USA), foram sensibilizadas com antígeno solúvel (10mg/ poço) diluído em tampão carbonato $0,05 \mathrm{M}$ pH 9,6 e incubadas overnight a $4^{\circ} \mathrm{C}$ para adsorção do mesmo na superfície da placa. Após a incubação, as placas foram lavadas com tampão PBS 0,02M pH 7,2, secas a $37^{\circ} \mathrm{C}$ por 10 minutos e armazenadas a $4^{\circ} \mathrm{C}$ até o momento do uso.

Para realização dos testes as placas foram inicialmente bloqueadas com $100 \mu \mathrm{l}$ de solução de albumina bovina $0,2 \%$ por cavidade e incubadas a $37^{\circ} \mathrm{C} / 1 \mathrm{~h}$. Os soros testes foram diluídos em PBS pH 7,2 (1:2.000), distribuídos nas placas (100 $\mu \mathrm{l} /$ poço) e incubados por uma hora a $37^{\circ} \mathrm{C}$. Cada amostra testada foi submetida a 2 repetições por placa e 5 repetições interplacas, totalizando 10 repetições por amostra. Após a incubação com anticorpo primário as placas foram lavadas quatro vezes com solução de lavagem (PBS 7,4 com $0,05 \%$ de Tween 20) e submetidas à incubação com anticorpo secundário espécie específico (anti-IgG conjugado com peroxidase), na diluição 1:10.000. A seguir, as placas foram novamente lavadas para, finalmente, receber $100 \mu 1$ do substrato cromogênico (orthophenylene-diamine, OPD) diluído em tampão citrato-fosfato $0,15 \mathrm{M}$ pH 5,0. Passados os 15 minutos, a reação foi bloqueada com $10 \mu \mathrm{l}$ de $\mathrm{H}_{2} \mathrm{SO}_{4} 4 \mathrm{~N}$, e a leitura realizada em espectofotômetro de microplacas, com filtro de $490 \mathrm{~nm}$.

Validação do teste. $O$ ponto de corte (cut-off) do teste foi calculado pela média das amostras negativas acrescida de três vezes o desvio padrão dessas amostras, onde o número de desvio-padrão utilizados na fórmula garante o nível de confiança do resultado (Soares 2001). Cut-off $=\mu \mathrm{DO}+3 \mathrm{x} s(99,8 \%$ de confiança $)$.

Para validação foram calculados a sensibilidade, especificidade, valor preditivo positivo e valor preditivo negativo do teste (Crowther 2001). A eficiência global do teste (Crowther 2001), também chamada de precisão (Paredes et al. 1999, Madruga et al. 2000, Madruga et al. 2001, Teixeira et al. 2001), foi calculada e corresponde ao percentual de indivíduos corretamente classificados como doentes ou saudáveis. As fórmulas utilizadas para os cálculos de validação são apresentadas nos Quadros 2 e 3.

\section{RESULTADOS}

$O$ ponto de corte foi calculado com base na média da densidade ótica (DO) das 120 amostras de soro de eqüinos e coelhos saudáveis. Para tal, foram considerados os valores obtidos em 10 repetições, em 5 placas diferentes. Os resultados com seu respectivo ponto de corte são apresentados no Quadro 1.

Para validação do teste, as amostras de soro de eqüinos com pitiose foram usadas juntamente com as amostras de animais normais. Dos 44 soros de eqüinos infectados naturalmente por Pythium insidiosum analisadas no ELISA, um apresentou reação falso-negativa, correspondendo a uma sensibilidade de $97,72 \%$. As 72 amostras de soro de eqüinos livres da infecção por $P$. insidiosum testadas no ELISA, sete apresentaram reações falsopositivas, o que corresponde a uma especificidade de $90,27 \%$.

\section{Quadro 1. Resultados e ponto de corte do ELISA com soros de eqüinos (infectados naturalmente pelo Pythium insidiosum) e coelhos (inoculados com antígenos do fungo)}

\begin{tabular}{lcc}
\hline & Eqüinos & Coelhos \\
\hline Média dos soros negativos $(\mu \mathrm{DO})$ & 0,076 & 0,063 \\
Desvio padrão (s) & 0,0168 & 0,014 \\
Ponto de corte (cut-off) & 0,126 & 0,105
\end{tabular}


Quadro 2. Resultado e validação ${ }^{a}$ do ELISA para o diagnóstico sorológico da pitiose em eqüinos infectados naturalmente

\begin{tabular}{cccc}
\hline \multirow{2}{*}{$\begin{array}{c}\text { Resultado } \\
\text { do ELISA }\end{array}$} & \multicolumn{3}{c}{ Eqüinos com pitiose } \\
\cline { 2 - 4 } & Positivos & Negativos & Total \\
\hline Positivo & $43(\mathrm{a})$ & $7(\mathrm{~b})$ & $50(\mathrm{a}+\mathrm{b})$ \\
Negativo & $1(\mathrm{c})$ & $65(\mathrm{~d})$ & $66(\mathrm{c}+\mathrm{d})$ \\
Total & $44(\mathrm{a}+\mathrm{c})$ & $72(\mathrm{~b}+\mathrm{d})$ & $116(\mathrm{a}+\mathrm{b}+\mathrm{c}+\mathrm{d})$
\end{tabular}

a De acordo com Crowther (2001) e Soares (2001).- Sensibilidade: (a)/(a+c x $100=43 / 44$ x $100=97,72 \%$. Especificidade: $(d) /(b+d)$ x $100=65 / 72$ x $100=90,27 \%$. Valor preditivo positivo: $(\mathrm{a}) /(\mathrm{a}+\mathrm{b})$ x $100=43 / 50 \times 100$ $=86,0 \%$. Valor preditivo negativo: $(\mathrm{d}) /(\mathrm{c}+\mathrm{d}) \times 100=65 / 66 \times 100=$ 98,4\%. Eficiência global (precisão): $(a+d) /(a+b+c+d)$ x $100=108 / 116$ $\mathrm{x} 100=93,1 \%$

Quadro 3. Resultado e validação ${ }^{a}$ do ELISA para diagnóstico sorológico em coelhos inoculados com antígenos de Pythium insidiosum

\begin{tabular}{cccc}
\hline Resultado & \multicolumn{3}{c}{ Coelhos } \\
\cline { 2 - 4 } do ELISA & Positivos & Negativos & Total \\
\hline Positivo & $22(\mathrm{a})$ & $2(\mathrm{~b})$ & $24(\mathrm{a}+\mathrm{b})$ \\
Negativo & $2(\mathrm{c})$ & $46(\mathrm{~d})$ & $48(\mathrm{c}+\mathrm{d})$ \\
Total & $24(\mathrm{a}+\mathrm{c})$ & $48(\mathrm{~b}+\mathrm{d})$ & $72(\mathrm{a}+\mathrm{b}+\mathrm{c}+\mathrm{d})$
\end{tabular}

${ }^{a}$ De acordo com Crowther (2001) e Soares (2001).- Sensibilidade: (a)/(a+c) x $100=22 / 24$ x $100=91,66 \%$. Especificidade: $(d) /(b+d)$ x $100=46 / 48$ x $100=95,83 \%$. Valor preditivo positivo: $(\mathrm{a}) /(\mathrm{a}+\mathrm{b})$ x $100=22 / 24 \times 100$ $=91,66 \%$. Valor preditivo negativo: $(\mathrm{d}) /(\mathrm{c}+\mathrm{d}) \times 100=46 / 48 \times 100=$ 95,83\%. Eficiência global (precisão): $(a+d) /(a+b+c+d) \times 100=68 / 72 \times$ $100=94,44 \%$.

Os valores preditivos positivos e negativos foram, respectivamente, $86 \%$ e $98,4 \%$. Os resultados de validação do teste para diagnóstico de pitiose encontram-se no Quadro 2.

Dentre os coelhos imunizados, dois apresentaram valores falso-negativos, correspondendo a sensibilidade de 91,66\%; entre os coelhos saudáveis dois foram falso-positivos, resultando em uma especificidade de $95,83 \%$. Os valores preditivos positivo e negativo foram, respectivamente, $91,66 \%$ e 95,83 . Os resultados do ensaio com soro de coelhos são apresentados no Quadro 3.

\section{DISCUSSÃO}

Tradicionalmente, o diagnóstico da pitiose no Brasil baseia-se nos dados clínico-epidemiológicos confirmados pelo exame histopatológico e/ou micológico. O diagnóstico é relativamente fácil em casos crônicos, porém, lesões cutâneas iniciais ou sistêmicas são de difícil detecção pelos métodos tradicionais e influenciam decisivamente no sucesso do tratamento (Leal et al. 2001b). No aspecto clínico a pitiose pode ser confundida com outras doenças como habronemose, basidiomicose e conidiobolomicose, doenças fúngicas com sinais semelhantes (Leal et al. 2001b). O exame histopatológico é auxiliar no diagnóstico e necessita de outras provas para confirmação, como a imunohistoquímica (Brown et al. 1988). O isolamento do agente requer colheita de material adequado e pode ser dificultado por contaminações secundárias da lesão. A correta identificação do $P$. insidiosum deve incluir a indução de zoosporogênese (Mendoza et al. 1987, Leal et al. 2001b), que demanda tempo e pessoal treinado. $O$ diagnóstico imunológico, pela técnica de ensaio imunoenzimático indireto (ELISA), possibilita a detecção de infecções precoces ou ainda subclínicas (Mendoza et al. 1997). A técnica de ELISA detecta anticorpos específicos com alto grau de sensibilidade e especificidade, sendo de execução relativamente fácil e rápida. As vantagens de técnicas imunológicas como imunodifusão, fixação do complemento, imunohistoquímica e ELISA já foram descritas por outros autores (Miller \& Campbell 1982, Brown et al. 1988, Kaufman \& Mendoza 1990, Imwidthaya \& Srimuang 1989, Mendoza et al. 1997), destacando-se a última como a mais eficiente para o diagnóstico da pitiose. Mendoza et al. (1997) sugerem o uso do ELISA indireto como forma de diagnóstico em áreas endêmicas, como é o caso do pantanal matogrossense. Entretanto, essas técnicas são pouco utilizadas no Brasil.

Segundo Paredes et al. (1999), um dos pontos críticos para o sucesso de técnicas como o ELISA indireto está na preparação do antígeno. O desvio padrão apresentado nos testes, tanto para amostras provenientes de equïinos quanto para as de origem cunícola, comprova a boa repetibilidade do ensaio, demonstrando a boa qualidade do antígeno produzido. Provavelmente a utilização de uma cepa reconhecida e de um protocolo baseado na sonicação do micélio, sejam fatores determinantes para a obtenção de um antígeno solúvel adequado ao diagnóstico.

A alta sensibilidade e a alta especificidade obtidas no presente ensaio imunoenzimático indireto demonstram a eficiência da sua utilização para o diagnóstico da pitiose em equiinos e coelhos, como também para a realização de monitoramento sorológico. Assim como na pitiose eqüina, em outras doenças a utilização de técnicas sorológicas parece ser bastante pertinente. Madruga et al. (2000) obtiveram resultados satisfatórios com a utilização de ELISA indireto para detecção de anticorpos contra o Anaplasma marginale. Paredes et al. (1999) buscaram padronizar este tipo de teste para o diagnóstico da peste suína clássica, tendo este se apresentado viável também para esta enfermidade. Em geral o diagnóstico de doenças fúngicas é feito principalmente por isolamento e identificação do agente. Um dos fatores de maior relevância para o diagnóstico da pitiose é a sua precocidade e, em nosso estudo foi possível detectar anticorpos contra $P$. insidiosum já aos quatorze dias após inoculação em coelhos. Essa capacidade é fundamental para detectar infecções na fase inicial, favorecendo o prognóstico. No decorrer das imunizações os valores de DO aumentaram, demonstrando o aumento no título de IgG em reposta aos antígenos de P. insidiosum inoculados.

A pitiose é considerada uma doença emergente (Vanittanakom et al. 2004) e foi recentemente descrita no Brasil em humanos (Bosco et al. 2005) e em ovinos (Tabosa et al. 2004), indicando que a existência de métodos diagnósticos seguros e eficazes são fundamentais para o monitoramento dessa enfermidade em nosso país. $O$ ensaio descrito nesse estudo pode ser adaptado para utilização em outras espécies. Por fim, o desenvolvimento de uma técnica de ELISA significa um avanço para o diagnóstico da pitiose, e permite também o monitoramento da resposta humoral em animais infectados e em tratamento por imunoterapia. 


\section{REFERÊNCIAS}

Alexopoulos C.J., Mims C.W. \& Blackwell M.1996. Phylum Oomycota, p.683737. In: Ibid. (ed.) Introductory Mycology. 4th ed. John Wiley \& Sons, New York.

Bosco S.M.G., Bagagli E., Araújo Jr J.P., Candeias J.M.G., Franco M.F., Marques M.E.A., Mendoza L., Camargo R.P. \& Marques S.A. 2005. Human pythiosis, Brazil. Emerging Inf. Diseases 11(5):715-718.

Brown C.C., McClure J.J., Triche P. \& Crowder C. 1988. Use of immunohistochemical methods for diagnosis of equine pythiosis. Am. J. Vet. Res. 19(11):1866-1868.

Chaifin M.K., Schumacher J. \& Hooper N. 1992. Multicentric Cutaneous Pythiosis in a foal. J. Am. Vet. Med. Assoc. 201(2):310-312.

Crowther J.R. 2001. The ELISA Guidebook. 1st ed. Humana Press, New Jersey, USA. 421p.

Foil C.S. 1996. Update on pythiosis (Oomycosis), p.57-63. In: Proc. North Am. Vet. Conference, Orlando. Bayer Animal Health, Orlando.

Grooters A.M. \& Gee M.K. 2002. Development of a nested polymerase chain reaction assay for the detection and identification of Pythium insidiosum. J. Vet. Intern. Med. 16:147-152.

Imwidthaya P. 1994. Human pythiosis in Thailand. Postgrad. Med. J. 70:558560 .

Imwidthaya P. \& Srimuang S. 1989. Immunodiffusion test for diagnosing human pythiosis. Mycopathologia 106:109-112.

Kaufman L., Mendoza L. \& Standard P.G. 1990. Immunodiffusion test for serodiagnosing subcutaneous zygomycosis. J. Clin. Microbiol. 28 (9):1887-1890.

Leal A.B.M., Leal A.T., Santurio J.M., Kommers G.D. \& Catto J.B. 2001a. Pitiose eqüina no Pantanal brasileiro: aspectos clínico-patológicos de casos típicos e atípicos. Pesq. Vet. Bras. 21(4):151-154.

Leal A.T., Leal A.B.M., Flores E.F. \& Santurio J.M. 2001b. Pitiose. Ciência Rural, Santa Maria, 31(4):735-743.

Madruga C.R., Araújo F.R., Marques A.P.C., Carvalho C.M.E., Cusinato F.Q., Crocci A.J., Kessler R.H. \& Miguita M. 2000. Desenvolvimento de uma prova de imuno-absorção enzimática para detecção de anticorpos contra Babesia bovis. Pesq. Vet. Bras. 20 (4):167-170.

Madruga C.R., Marques A.P.C., Araújo F.R., Miguita M., Carvalho C.M.E., Araújo F.S., Umaki A.C.S., Crocci A.J. \& Queiróz R.A. 2001. Evaluation of an ELISA for detection of antibodies to Babesia bigemina in cattle and its application in an epidemiological survey in Brazil. Pesq. Vet. Bras. 21(2):72-76.

Mendoza L. Arias M. Colmenarez V. \& Perazzo Y. 2005. Intestinal canine pythiosis in Venezuela confirmed by serological and sequencing analysis. Mycopathologia 159:219-222.

Mendoza L., Kaufman L. \& Standard P. 1987. Antigenic relationship between the animal and human pathogen Pythium insidiosum and nonpathogenic pythium species. J. Clin. Microbiol. 25(11):2159-2162.

Mendoza L., Kaufman L. \& Mandy W.G.R. 1997. Serodiagnosis of human and animal pythiosis using an enzime-linked immunosorbent assay. Clin. Diag. Lab. Immunol. 4(6):715-718.

Miller R.I. \& Campbell R.S.F. 1982. Immunological studies on equine phycomycosis. Aust. Vet. J. 58:227-231.

Paredes J.C.M., Oliveira L.G., Braga, A.C. Trevisol I.M. \& Roehe P.M. 1999. Development and standardization of an indirect elisa for the serological diagnosis of classical swine fever. Pesq. Vet. Bras. 19(3/4):123-127.

Santurio J.M., Monteiro A.B., Leal A.T., Kommers G.D., Sousa R.S. \& Catto, J.B. 1998. Cutaneous pythiosis insidiosi in calves from the Pantanal region of Brazil. Mycopathologia 141:123-125.

Santurio J.M., Leal A.T., Leal A.B.M., Alves S.H., Lubeck I. \& Griebeler J. 2001. Teste Elisa para o diagnóstico de Pitiose. III Congr. Bras. Micologia. Águas de Lindóia, SP, p.126.

Schurko A.M., Mendoza L., Cock A.W.A.M., Bedard J.E.J. \& Klassen G.R. 2004. Development of a species-specific probe for Pythium insidiosum and the diagnosis of pythiosis. J. Clin. Microbiol. 42(6):2411-2418.

Soares C.O. 2001. Princípios, padronização e validação de provas sorológicas, p.145-178. In: Madruga C.R., Araújo F.R., \& Soares C.O. Imunodiagnóstico em Medicina Veterinária. Embrapa Gado de Corte, Campo Grande, MS.

Tabosa I.M., Riet-Correa F., Nobre V.M.T., Azevedo E.O., Reis-Junior J.L. \& Medeiros R.M.T. 2004. Outbreaks of pythiosis in two flocks of sheep in northeastern Brazil. Vet. Pathol. 41:412-415.

Teixeira M.E.B., Esteves P.A., Schmidt C.S., Spilki F.R., Silva T.C., Dotta M.A. \& Roehe P.M. 2001. ELISA de bloquéio monoclonal para o diagnóstico sorológico de infecções pelo herpesvírus bovino tipo 1 (BHV-1). Pesq. Vet. Bras. 21(1):33-37.

Vanittanakom N., Supabandhu J., Khamwan C., Praparattanapan J., Thirach S., Prasertwitayakij N., Louthrenoo W., Chiewchanvit S. \& Tananuvat N. 2004. Identification of emerging human-pathogenic Pithium insidiosum by serological and molecular assay-based methods. J. Clin. Microbiol. 42(9):3970-3974. 